This article was downloaded by: [82.13.27.130]

On: 03 February 2013, At: 13:13

Publisher: Taylor \& Francis

Informa Ltd Registered in England and Wales Registered Number: 1072954 Registered office: Mortimer House, 37-41 Mortimer Street, London W1T 3JH, UK

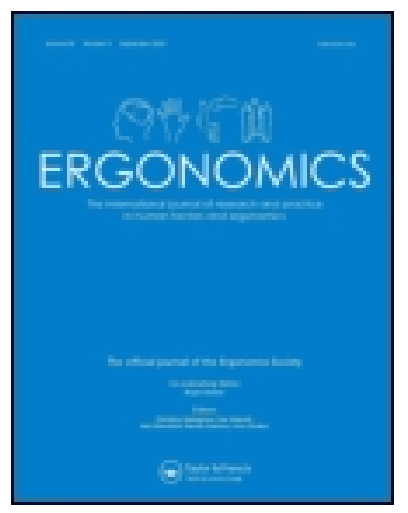

\title{
Ergonomics
}

Publication details, including instructions for authors and subscription information: http://www.tandfonline.com/loi/terg20

\section{A strategy for human factors/ergonomics: developing the discipline and profession}

Jan Dul $^{a}$, Ralph Bruder ${ }^{b}$, Peter Buckle ${ }^{c}$, Pascale Carayon ${ }^{d}$, Pierre Falzon ${ }^{e}$, William S. Marras $^{f}$, John R. Wilson ${ }^{g}$ \& Bas van der Doelen ${ }^{h}$

${ }^{a}$ Rotterdam School of Management, Erasmus University, Rotterdam, the Netherlands

${ }^{\mathrm{b}}$ Institute of Ergonomics, Technische Universität Darmstadt, Germany

${ }^{c}$ Imperial College, Department of Surgery and Cancer, Faculty of Medicine, London, UK

${ }^{\mathrm{d}}$ Center for Quality and Productivity Improvement, Department of Industrial and Systems Engineering, University of Wisconsin-Madison, Madison, USA

${ }^{\mathrm{e}}$ Research Center on Work and Development, Cnam, Paris, France

${ }^{f}$ The Ohio State University, Biodynamics Laboratory, USA

${ }^{g}$ Human Factors Research Group, Faculty of Engineering, University of Nottingham, UK

${ }^{\mathrm{h}}$ Department of Knowledge and Communication, BMA Ergonomics, Zwolle, the Netherlands Version of record first published: 15 Feb 2012.

To cite this article: Jan Dul, Ralph Bruder, Peter Buckle, Pascale Carayon, Pierre Falzon , William S. Marras, John R. Wilson \& Bas van der Doelen (2012): A strategy for human factors/ergonomics: developing the discipline and profession, Ergonomics, 55:4, 377-395

To link to this article: http://dx.doi.org/10.1080/00140139.2012.661087

\section{PLEASE SCROLL DOWN FOR ARTICLE}

Full terms and conditions of use: http://www.tandfonline.com/page/terms-and-conditions

This article may be used for research, teaching, and private study purposes. Any substantial or systematic reproduction, redistribution, reselling, loan, sub-licensing, systematic supply, or distribution in any form to anyone is expressly forbidden.

The publisher does not give any warranty express or implied or make any representation that the contents will be complete or accurate or up to date. The accuracy of any instructions, formulae, and drug doses should be independently verified with primary sources. The publisher shall not be liable for any loss, actions, claims, proceedings, demand, or costs or damages whatsoever or howsoever caused arising directly or indirectly in connection with or arising out of the use of this material. 


\title{
A strategy for human factors/ergonomics: developing the discipline and profession
}

\author{
Jan Dul $^{\mathrm{a} *}$, Ralph Bruder ${ }^{\mathrm{b}}$, Peter Buckle ${ }^{\mathrm{c}}$, Pascale Carayon ${ }^{\mathrm{d}}$, Pierre Falzon ${ }^{\mathrm{e}}$, \\ William S. Marras ${ }^{\mathrm{f}}$, John R. Wilson ${ }^{\mathrm{g}}$ and Bas van der Doelen ${ }^{\mathrm{h}}$

\begin{abstract}
${ }^{a}$ Rotterdam School of Management, Erasmus University, Rotterdam, the Netherlands; ${ }^{b}$ Institute of Ergonomics, Technische Universität Darmstadt, Germany; ' Imperial College, Department of Surgery and Cancer, Faculty of Medicine, London, UK; ${ }^{d}$ Center for Quality and Productivity Improvement, Department of Industrial and Systems Engineering, University of Wisconsin-Madison, Madison, USA; ${ }^{e}$ Research Center on Work and Development, Cnam, Paris, France; ${ }^{f}$ The Ohio State $U K,{ }^{h}$ Department of Knowledge and Communication, BMA Ergonomics, Zwolle, the Netherlands
\end{abstract} \\ University, Biodynamics Laboratory, USA; ${ }^{g}$ Human Factors Research Group, Faculty of Engineering, University of Nottingham,
}

(Received 7 December 2011; final version received 22 January 2012)

\begin{abstract}
Human factors/ergonomics (HFE) has great potential to contribute to the design of all kinds of systems with people (work systems, product/service systems), but faces challenges in the readiness of its market and in the supply of highquality applications. HFE has a unique combination of three fundamental characteristics: (1) it takes a systems approach (2) it is design driven and (3) it focuses on two closely related outcomes: performance and well-being. In order to contribute to future system design, HFE must demonstrate its value more successfully to the main stakeholders of system design. HFE already has a strong value proposition (mainly well-being) and interactivity with the stakeholder group of 'system actors' (employees and product/service users). However, the value proposition (mainly performance) and relationships with the stakeholder groups of 'system experts' (experts from technical and social sciences involved in system design), and 'system decision makers' (managers and other decision makers involved in system design, purchase, implementation and use), who have a strong power to influence system design, need to be developed. Therefore, the first main strategic direction is to strengthen the demand for high-quality HFE by increasing awareness among powerful stakeholders of the value of high-quality HFE by communicating with stakeholders, by building partnerships and by educating stakeholders. The second main strategic direction is to strengthen the application of high-quality HFE by promoting the education of HFE specialists, by ensuring highquality standards of HFE applications and HFE specialists, and by promoting HFE research excellence at universities and other organisations. This strategy requires cooperation between the HFE community at large, consisting of the International Ergonomics Association (IEA), local (national and regional) HFE societies, and HFE specialists. We propose a joint world-wide HFE development plan, in which the IEA takes a leadership role.
\end{abstract}

Practitioner Summary: Human factors/ergonomics (HFE) has much to offer by addressing major business and societal challenges regarding work and product/service systems. HFE potential, however, is underexploited. This paper presents a strategy for the HFE community to strengthen demand and application of high-quality HFE, emphasising its key elements: systems approach, design driven, and performance and well-being goals.

Keywords: human factors/ergonomics discipline, human factors/ergonomics profession, future of ergonomics, work systems, product/service systems, performance

\section{Introduction}

This paper provides a vision of the future of the human factors/ergonomics (HFE) discipline and profession (the terms ergonomics and human factors are used interchangeably ${ }^{1}$ ). The paper presents the findings of the Future of Ergonomics Committee ${ }^{2}$, which was established in December 2010 by the International Ergonomics Association (IEA) and which reported its results at the 18th Triennial World Congress on Ergonomics, IEA2012 in Brazil. The goal of the committee was to formulate a position paper for the HFE community on strategies for the future of the HFE discipline and profession. During the more than 50 years of HFE history, several papers have been published discussing the future of ergonomics. Recent examples include special issues in Theoretical Issues in Ergonomics Science (Hollnagel 2001) and Ergonomics (Stanton and Stammers 2008). Most papers predict the future of ergonomics for specific HFE areas in terms of expected developments and effects on the content of the discipline, or in specific regions. In contrast, the present paper focuses on a strategy for the world-wide promotion of the discipline and profession in order to reach global excellence in HFE. The paper does not contain an operational plan to realise this strategy.

\footnotetext{
*Corresponding author. Email: jdul@rsm.nl
} 
The committee developed a strategy for the future of HFE by sharing and discussing the views of committee members and many other HFE specialists. Besides electronic communication among committee members, the committee held physical meetings in Amsterdam (March 2011, November 2011) and Paris (June 2011), and had a brainstorming session with IEA council members in Grahamstown, South Africa (April 2011). Inputs from many other HFE specialists worldwide were obtained via face-to-face interviews and email exchange (a list of people who provided input can be found in the Acknowledgements). Although the committee has collected many documents on the future of HFE, the views expressed in this paper are not based on this literature or on a literature review. However, we added references for illustration and further reading. This paper presents the final view of the committee. The committee consists mainly of western academics with extensive international experience, and with substantial experience of working closely with practitioners and clients in all areas of industry and commerce. This document is not a 'consensus' paper representing all views in the HFE community, nor does it necessarily reflect the view of the IEA. The content is available to any organisation (including the IEA and local HFE societies) and any individual to develop new strategies, tactics and operations within their own context.

The starting point of this paper is that HFE has great potential to ensure that any designed artefact, ranging from a consumer product to an organisational environment, is shaped around the capacities and aspirations of humans, such that performance and well-being are optimised. When HFE does not play a role in system design, this can lead to sub-optimal systems with quality deficits, reduced efficiency, illness, dissatisfaction, etc. HFE can provide solutions to these problems. However, the potential of HFE remains under-exploited. At least four reasons have been identified. First, many stakeholders involved in the design, management and use of artefacts (e.g. customers, workers, managers, other professionals, society at large) are not aware of the value of HFE and as a consequence, do not exhibit a strong demand for HFE. Second, in certain situations where there is a demand for HFE (e.g. 'ergonomic products' in product marketing, 'ergonomic systems' in safety critical industries such as defence, transport, oil, and healthcare), there is not enough high-quality HFE in the design process because HFE is lacking or its application is too limited in scope, resulting in sub-optimal solutions. Third, the field is very small in comparison to established disciplines involved in designing artefacts like engineering and psychology, and is often incorporated within these disciplines without explicit reference to the HFE discipline. Fourth, the very strength of HFE, its multi-disciplinary base, is also a potential weakness; a diversity of topics, views and practices exist within the HFE community, resulting in unclear communication to the external world.

In order to develop a strategy for the HFE discipline and profession, we start by describing the fundamental characteristics of HFE in Section 2. Then, we identify developments in the external world that are important for HFE in Section 3. Next, we formulate the value of HFE for the main stakeholders of system design. In Section 5, we propose the strategic positioning of the HFE discipline, and finally we discuss possible strategic actions for the HFE community that can help to achieve a prosperous future for HFE.

\section{The fundamental characteristics of the HFE discipline and profession}

HFE focuses on systems in which humans interact with their environment. The environment is complex and consists of the physical environment ('things'), the organisational environment (how activities are organised and controlled), and the social environment (other people, culture) (Moray 2000, Wilson 2000, Carayon 2006). The system can be a work system (where the human is a worker and the environment is the work environment) or a product/service system (where the human is a product user or person who receives a service and the environment is the environment where the product is used or where the service is received $)^{3}$. The focus of HFE is to jointly improve performance and well-being by designing the integrative whole better, and by integrating the human into the system better. This is done by fitting the environment to the human. HFE typically takes a hierarchical approach where environmental design to fit the human is seen as the priority, and selecting people to fit the environment or training people to fit the system is only considered when the former is not possible. With a better fitting environment, humans are better able to contribute to performance ${ }^{4}$. Over the past $50+$ years, the HFE community has developed and documented a substantial body of knowledge and skills regarding interactions between humans and their environment, and methodologies for analysing and designing systems.

The definition of HFE and HFE specialists (adopted by the IEA in 2000) reflects this body of knowledge as follows (IEA 2000):

'Ergonomics (or human factors) is the scientific discipline concerned with the understanding of the interactions among humans and other elements of a system, and the profession that applies theoretical principles, data and methods to design in order to optimize well-being and overall performance.' 
'Practitioners of ergonomics, ergonomists, contribute to the planning, design, implementation, evaluation, redesign and continuous improvement of tasks, jobs, products, technologies, processes, organisations, environments and systems in order to make them compatible with the needs, abilities and limitations of people.'

Three fundamental characteristics of HFE can be derived from these descriptions:

- HFE takes a systems approach.

- HFE is design driven.

- HFE focuses on two related outcomes: performance and well-being.

\subsection{HFE takes a systems approach}

A system is a set of interacting and interdependent components that form an integrated whole. HFE focuses on goal-oriented and purposefully designed systems consisting of humans and their environment (Helander 1997, Schlick 2009). The environment can be any human-made artefact e.g. (work)place, tool, product, technical processes, service, software, built environment, task, organisational design, etc. as well as other humans (Wilson 2000). HFE considers different aspects of the person (physical, physiological, psychological (affective and cognitive), and social) and different aspects of the environment (physical, social, informational, etc.). It can address issues on various system levels from micro-level (e.g. humans using tools or performing single tasks) to meso-level (e.g. humans as part of technical processes or organisations) to macro level (e.g. humans as part of networks of organisations, regions, countries, or the world) (Rasmussen 2000). When defining problems and formulating solutions, system boundaries are defined, and the focus of HFE can be on specific aspects of people (e.g. only physical), on specific aspects of the environment (e.g. only workplace), or on a specific level (e.g. micro), but the broader context of the human within the environment is always taken into consideration ('contextualisation'). This broad perspective of HFE can be referred to as a 'systems approach' or a 'holistic approach.'

The systems or holistic approach of HFE and its wide (almost unlimited) context for application differentiates it from other more narrow disciplines such as cognitive psychology and human movement science (Brewer and Hsiang 2002). These other disciplines may share a human view with HFE, but not a comprehensive view.

\subsection{HFE is design driven}

HFE seeks to improve performance and well-being through systems design. Analyses and assessments result in recommendations and actions for this design. HFE can be involved in all stages of planning, design, implementation, evaluation, maintenance, redesign and continuous improvement of systems (Japan Ergonomics Society 2006). These stages are not necessarily sequential; they are recursive, interdependent, dynamic, but design is at the heart of them. Decisions at one stage may affect or be affected by decisions at other stages.

HFE specialists can be active participants in design processes, and a particular feature of HFE is that those who will be part of the system being designed are often brought into the development process as participants (Noro and Imada 1991). HFE specialists can have different roles. For example, they can act as specialists of the human component of the system. The human component should be understood as covering both individual and collective or social aspects, from micro to macro level. HFE specialists have competencies regarding methods for analysing and acting on situations, methods for designing and assessing technical and organisational environments, methods for organising and managing participatory approaches, and methods for redesigning and continuously improving systems (Woods and Dekker 2000). HFE specialists analyse and solve problems in partnership with other contributors to design (Noy 1995, Rasmussen 2000). They can also play an integrative role in design decisions, based on their knowledge and skills of design as an activity (including mental processes of contributors to the design, and collective interaction processes). Furthermore, they can stimulate and moderate design processes by, for instance, translating engineering terminology or concepts to end-user terminology and vice versa.

This design orientation of HFE differentiates it from other disciplines such as sociology, and anthropology. These other disciplines may share a comprehensive view with HFE, but not an action view (Helander 1997).

\subsection{HFE focuses on two related outcomes: performance and well-being}

By fitting the environment to the human, two related system outcomes can be achieved: performance (e.g. productivity, efficiency, effectiveness, quality, innovativeness, flexibility, (systems) safety and security, reliability, sustainability) and well-being (e.g. health and safety, satisfaction, pleasure, learning, personal development). These 
and other outcomes are balanced by HFE specialists, managing practical as well as ethical trade-offs within systems (e.g. Wilson et al. 2009). Performance and well-being interact: performance can influence well-being, and well-being can influence performance, both in the short and the long-term (see Figure 1).

Reduced performance and well-being can occur when there is a lack of fit between the environment and human capabilities and aspirations. For example, humans may perform below their capabilities and standards because other parts of the system are an obstacle rather than a supporting environment (e.g. due to lack of time, inappropriate equipment, insufficient support) (Falzon 2005, Falzon et al. 2012). Well-being and performance are intertwined and should be understood as strongly connected (Pot and Koningsveld 2009).

HFE recognises that any system always produces two outcomes: performance and well-being. By fitting the environment to the human, HFE can contribute to optimising ${ }^{5}$ these joint outcomes (Neumann and Dul 2010).

This focus of HFE on two joint outcomes is a differential characteristic. Other disciplines such as engineering, psychology, and medicine share the focus on one of the outcomes with HFE, but not on both outcomes.

\section{Developments in the external world (general description)}

Developments in the world are having major impacts on systems. These developments and their significance for HFE need to be identified (Hendrick 1991, Noy 2000, Japan Ergonomics Society 2006) in order to set out a strategy for the future. Without attempting to be complete, we describe some global trends regarding changes that impact HFE.

\subsection{Global change of work systems}

The change in the global economic landscape over the last decade has resulted in a significant shift in the types of work that occur in different regions of the world. These changes have occurred in economically advanced nations, as well as in economically developing nations. Historically, economically advanced nations have been heavily involved in mass goods manufacturing. However, over the past two decades, these nations have increasingly outsourced manufacturing and service functions to economically developing countries, within a supply chain and global market perspective. This has shifted the work performed within the economically advanced nations to an emphasis on a service economy (including healthcare services), resulting in more focus on the design of work systems for service production, and on the design of non-work systems such as services for customers and human-computer interactions (Drury 2008, Hedge and Spier 2008). Additionally, stimulation of entrepreneurship has resulted in a growing number of small-sized and informal businesses in some economically advanced nations.

At the same time, economically developing countries have enlarged their manufacturing base, thus creating more jobs. As a result, work, historically based on local agriculture, has shifted towards more emphasis on manufacturing (often without the HFE benefits found in economically advanced nations). Goods are often produced by workers earning low wages and working under unfavourable conditions. Sharp increases in manufacturing are occurring because of the low cost of goods production. In addition, many of these economically developing nations are simultaneously experiencing an increase in low wage service sector jobs (e.g. call centres, banking). At the same time, in some countries, the informal sector involves the largest number of workers (Caple 2008) and agriculture remains the principal sector contributing to the country's economic performance, including sometimes children who carry out tasks for very low or no wages (Gangopadhyay et al. 2004).

Furthermore, there is a continuing trend of mechanisation and automation of work systems, not only in manufacturing but also in the service industry (Schlick 2009). The introduction of more technology and increased

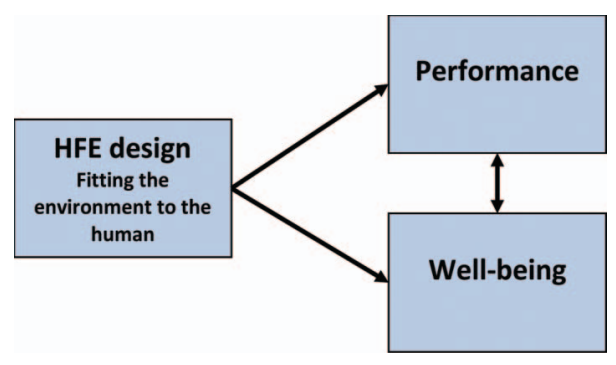

Figure 1. The effect of HFE design on performance and well-being. 
capabilities of technology (many times beyond human capabilities) may change the relationship between people and technology.

\subsection{Cultural diversity}

One major impact of the trends described above is the increased interdependencies between economies, industries and companies around the world. Consequently, production and distribution systems are internationally organised with a culturally diverse workforce, and products and services are consumed by an increasingly diverse set of customers in markets around the world. As a result, a diverse set of humans with different cultural backgrounds, and different characteristics and aspirations has become part of work and product/consumer systems. Environments that were properly designed for one group of people may not be appropriate for other groups of people.

HFE can address this trend of cultural diversity by contributing to the cross-cultural design of production and distribution systems that fit the diverse workforce, and to the cross-cultural design of products and services that fit the diversity of users (Moray 2000, Japan Ergonomics Society 2006). In cross-cultural design, it is acknowledged

that people from different cultures have different capabilities and aspirations, which affect the design of systems of which they are part. Examples include the design of global supply chains (Riedel and Mueller 2009) and the design of international digital media (Proctor et al. 2011).

\subsection{Ageing}

Several parts of the world are experiencing a demographic change known as population ageing, brought about by a combination of longer life expectancy, declining fertility, and the progression through life of a large 'baby boom' generation. In the USA, the workforce is ageing; in Europe the proportion of older people in the working populations in European countries is increasing more than in other continents. In India, the retirement age of office or industrial workers has recently been raised. As a consequence, a large group of older humans have become part of work and product/service systems. Environments that were designed for the current group of humans may not be as suitable for elderly people in the system. Another consequence of ageing is the increased relevance of equipment, furniture, IT devices, services, etc. targeting the older population at work, and adapted to their characteristics.

HFE can contribute by ensuring that work systems and products/services fit the older population, taking into account age-related changes in physical, cognitive, visual and other capabilities, and different aspirations (Japan Ergonomics Society 2006). Older people may have some reduced capabilities, but also more developed capabilities such as mental growth (strategic thinking, language skills, motivation, commitment, work expertise) and some aspects of social capabilities (ability to adjust their behaviour). However, there are large variations among older age groups, and these can become more pronounced with age (Ilmarinen 2005).

HFE can help develop more versatile systems that are better matched to a wide range of groups. This approach does not only apply to people of different age groups, but also to people with disabilities, obesity (Buckle and Buckle 2011), or otherwise different capabilities and aspirations ('design for all'). However, this ageing trend is not global. In other parts of the world, e.g. Sub-Saharan African countries, life expectancy is on the decline because a large part of the population is suffering from HIV and related illnesses. In these countries, the main concern is having a sustainable workforce that can meet the requirements of the job market.

\subsection{Information and communication technology (ICT)}

There are several ICT-related changes that impact the manner in which work and activities of daily living are performed (Karwowski 2006). Rapid and continuous developments in computer technology, telecommunication technology and media technology have given rise to new interactive activities such as social media, gaming, and to an explosion of information transfer. People's lives have become more and more dependent on ICT and virtual networks. For example, these developments have an impact on the delivery of education. Similarly, new dimensions in product quality have emerged beyond usability, such as emotional design and pleasurable interactions.

ICT developments have brought about many changes in work organisation and organisational design. These include more focus on teamwork, the rise of virtual organisations, remote work including working from home, fading borders between occupational and private life, and increased complexity of networks of organisations (Carayon and Smith 2000). 
Networks of organisations have emerged as an organisational model to support collaboration between organisations that have common goals. Very often organisational networks rely on technology to communicate and share information, for instance, supply chains in manufacturing. Another example is the exchange of health information, which allows different healthcare organisations to share information about patients.

Increasingly, companies are relying on virtual arrangements to conduct their business. Virtual sociotechnical systems comprising diverse people, who are geographically dispersed, use information and communication technologies to perform their work remotely (Gibson and Gibbs 2006).

HFE specialists can contribute to the design of systems to allow people to work together and share information across organisational boundaries (Woods and Dekker 2000). For example, HFE can influence the design of virtual sociotechnical systems by showing how trust and collaboration can be enhanced when team members work remotely and communicate via technology (Patel et al. 2012). HFE can also contribute to the design of natural user interfaces in human-computer interactions.

\subsection{Enhanced competitiveness and the need for innovation}

The enhanced competitiveness among companies, which is partly a result of globalisation, has forced companies to develop new business strategies, and has increased the need for companies to innovate and invent new products and services, as well as new ways of producing these. Employees may contribute to suggestions for the innovation of production processes and products/services. Production processes need to be more efficient and flexible and must guarantee short product delivery times, often resulting in intensification of work. Products and services must have high quality characteristics beyond functionality, e.g. ease of use and positive user experiences, to be successful in the market and to gain commercial advantage.

HFE can contribute to the renewal of business strategies and innovation in several ways (Dul and Neumann 2009). HFE can foster employee creativity for innovation (Dul and Ceylan 2011), can contribute to product/service innovation by developing new products and services with unique usability and experience characteristics, and can help a company to innovate processes and operations by providing new efficient and effective ways of producing products and services (Broberg 1997, Bruder 2000).

\subsection{Sustainability and corporate social responsibility}

Sustainability -the development that meets the needs of the present without compromising the ability of future generations to meet their own needs- includes attention to natural and physical resources ('planet'), but also attention to human and social resources ('people'), in combination with economic sustainability ('profit') (Delios 2010, Pfeffer 2010). It implies that companies do not just focus on financial performance. Corporate Social Responsibility (CSR) means going beyond fulfilling the minimum legal expectations regarding 'planet' and 'people'. Poor or minimum standards in health and safety may damage a company's image with respect to CSR, which would be a direct threat to the value of the CSR effort and the continuity of the business. HFE can contribute to developing actions and programmes aimed at combining the people and profit dimension of sustainability and social responsibility by optimising both performance and well-being (Pfeffer 2010, Zink 2005, 2006).

In many economically developing countries, the understanding of the human element requires knowledge of complex social and cultural environments. For example, in South Africa, the workforce is often faced with issues such as HIV, cardiovascular diseases, infectious diseases other than HIV, and intentional violence. These issues influence the work capacity of the population. HFE specialists in these countries, therefore, have a significant role to play in improving both performance (e.g. productivity) and well-being.

In conclusion, the above and other examples of developments illustrate that systems change because the human part or the environment part of the system (or both) change. By offering its fundamental characteristics, HFE has the potential to contribute to the design of future systems.

\section{The value of HFE for stakeholders}

The contribution of HFE to system design ('supply of HFE') depends on the 'demand for HFE' by parties ('stakeholders') involved in system design. Demand for HFE depends on the perceived value of HFE by stakeholders that are directly or indirectly involved in system design. To be able to supply, HFE must show that it can provide value to these stakeholders in order to be a respected and demanded partner in the design process. 
In this section, we first identify the main stakeholder groups for system design. Next, we describe how the stakeholder groups could benefit from the contribution of HFE in systems design. Finally, we evaluate the (mis)match between the potential, perceived and provided value of HFE.

\subsection{Stakeholders of system design}

Four main stakeholders groups of system design can be identified:

- 'System actors', i.e. employees, product/service users, who are part of the system and who are directly or indirectly affected by its design and who, directly or indirectly, affect its performance.

- 'System experts', i.e. professionals such as engineers and psychologists who contribute to the design of the system based on their specific professional backgrounds. The HFE specialist is one of the system experts who focuses on design by fitting the environment to humans, by using a systems approach, and by focusing on two related outcomes (performance and well-being).

- 'System decision makers', i.e. decision makers (e.g. managers) about the (requirements for) the system design, the purchasing of the system, its implementation and its use.

- 'System influencers', i.e. media, governments, standardisation organisations, regulators, citizens who have general public interest in work system and product/service system design.

For each of the main stakeholder groups, we distinguish four levels of stakeholders: individual (the direct stakeholder), company, country/region, and world (the indirect stakeholders). A stakeholder at a 'broader' level (e.g. country) may represent a stakeholder at a more narrow level (e.g. company). Table 1 describes in more detail examples of stakeholders from the main stakeholder groups that are directly or indirectly involved in or affected by systems design. As a reference, we have included the HFE specialist as one of the 'system experts'.

It should be noted that people can belong to different stakeholder groups depending on their role. For example, employees who are part of a work system are system actors. However, they become system experts (based on their experience) when they participate in the (re)design of a system. Similarly, managers who decide about system designs are system decision makers, but when the systems are implemented and the managers have management tasks in the new systems, they become system actors.

\subsection{Value of HFE for stakeholders}

In this section, we describe the value of HFE contributions to systems design for the main stakeholder groups (individuals and their representing organisations at company, national and international level).

\subsubsection{System actors}

This stakeholder group can be divided into actors of work systems (employees), and actors of product/service systems (product users, service receivers).

Employees can benefit from HFE design of work systems as it ensures well-being in terms of e.g.:

- Improved physical, psychological and social well-being (health and safety) (e.g. through optimisation of work environments).

- Higher motivation, growth and job satisfaction (e.g. through freedom to act and room to grow and learn).

- Improved performance (e.g. performance leading to intrinsic or extrinsic reward).

Product users/service receivers can benefit from HFE design of product/service systems as it ensures well-being and performance in terms of e.g.:

- Better experience

- Shorter time of familiarisation

- Better fitting of products/services to individual characteristics/needs

- Fewer mistakes

- Greater efficiency 
$J . D u l$ et al.

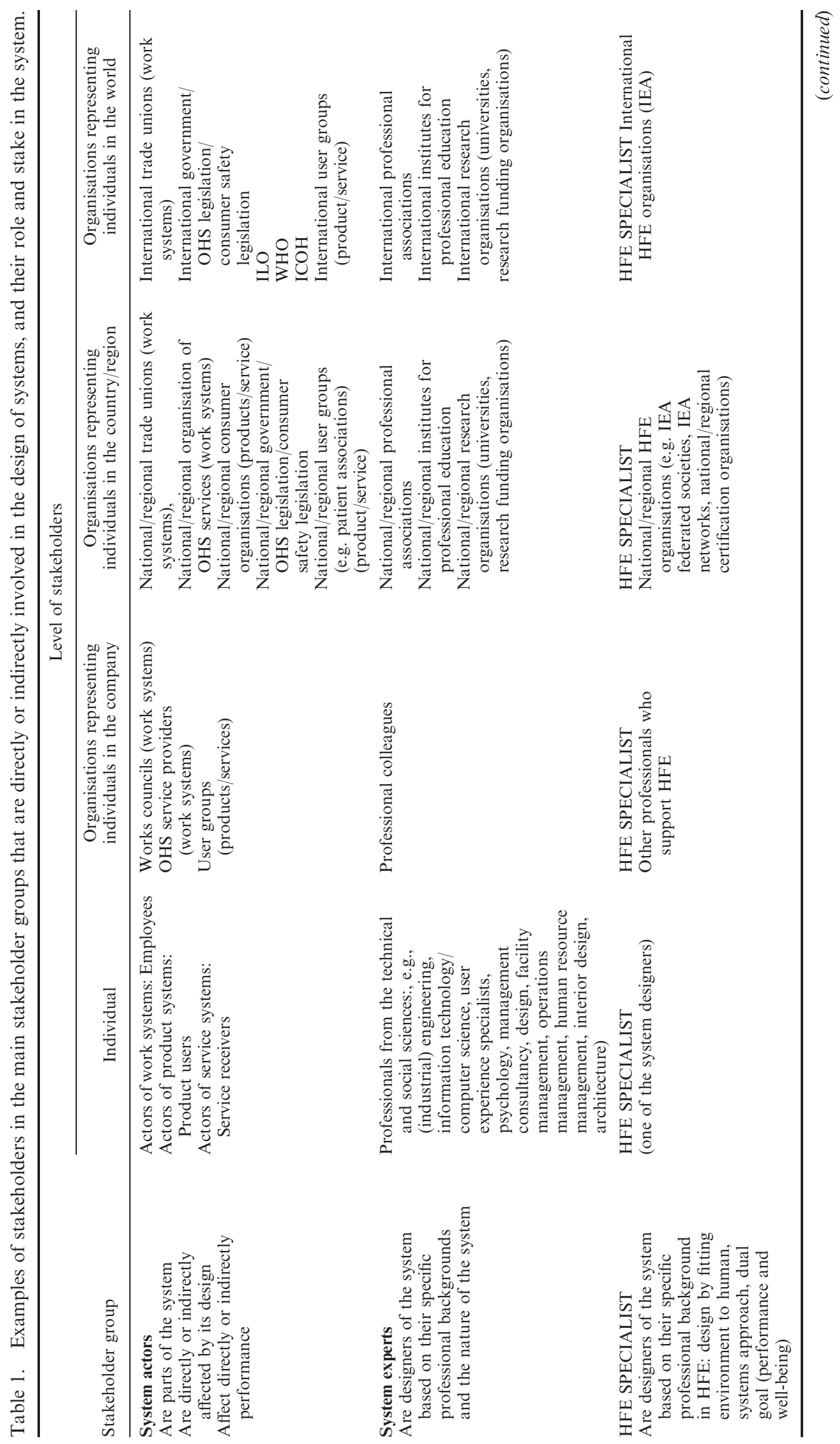


Ergonomics

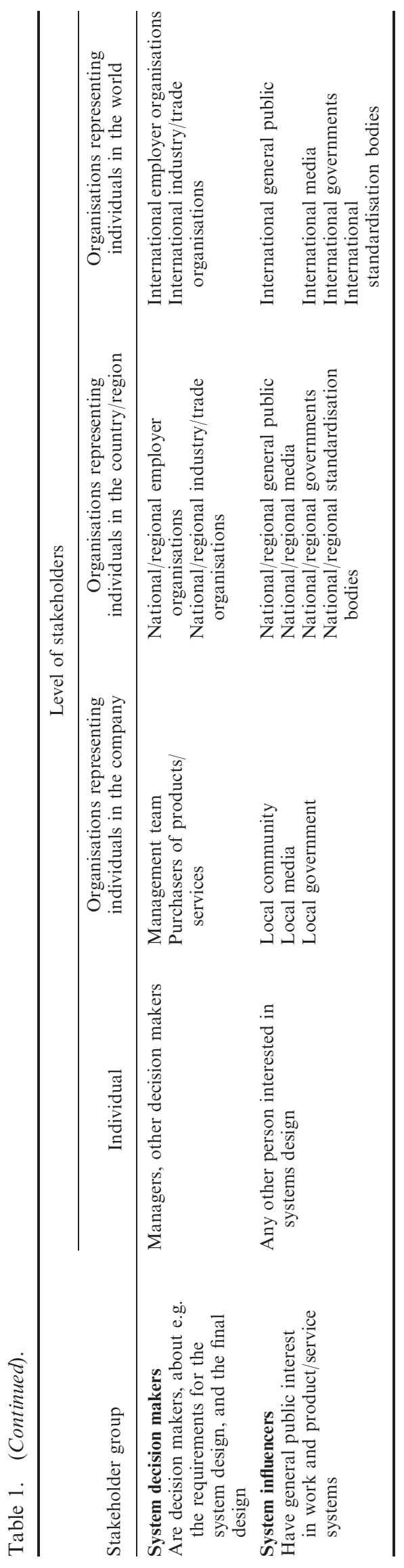


In addition, as HFE commonly takes participatory design approaches, another potential value of HFE is that it ensures that system actors can influence system design.

\subsubsection{System experts}

This stakeholder group consists of a variety of professionals from the technical and social sciences that can be involved in the design of systems, e.g. (industrial) engineering, information technology/computer sciences, psychology, management consultancy, design, facility management, operations management, human resource management, interior design, architecture. These professionals aim to design a system that performs well according to the standards of their respective professions, and to the requirements of system decision makers. HFE can help to reach these goals because HFE contributions help to ensure:

- Better users' acceptance of designed systems

- Better performance

- Better fit with (legal) standards (e.g. health and safety, accessibility, professional ethics)

- Improved development process (e.g. more efficient user consultation).

\subsubsection{System decision makers}

This stakeholder group consists of decision makers (e.g. managers, purchasers) that decide about the design (e.g. requirements, final design) of work systems and product/service systems.

Management (e.g. in companies) aims to achieve excellent performance of work systems with the least use of resources. Typical key performance indicators of work systems are productivity (the number of produced products and services per time), the time needed for fulfilling a certain task, and the quality of products/ services.

Decision makers about work systems can benefit from HFE as it ensures performance in terms of e.g.:

- Better productivity by reduced time for performing work procedures (e.g. through optimisation of work equipment, work flow or worker qualifications).

- Better quality and reliability of production processes and produced goods and services (e.g. through optimisation of work equipment, operating instructions or worker qualifications).

- Lower operating costs due to lower levels of health problems, motivational deficits, accidents, absenteeism, and related productivity loss (e.g. through better working conditions).

- More innovation by increased employee creativity (e.g. through creativity stimulating work environments).

- Better reputation for hiring and retention of talented employees (e.g. through attractive work), and positive worker and consumer associations with the firm and its products/services (employee well-being, sustainability, corporate social responsibility, end user well-being).

- Better decision-making through improved information about the effects of system design on employees.

Decision makers about product/service systems can benefit from HFE design as it ensures product/service performance in terms of:

- Better market performance (e.g. due to unique characteristics such as ease of use).

- Greater profitability.

- Less re-design due to interaction problems after market introduction.

- Better decision-making by improved information about effects of system design on product/service users.

\subsubsection{System influencers}

System influencers have a general public interest in work and product/service systems, in particular regarding their outcomes. HFE can contribute simultaneously to two general goals:

- Social wealth of individuals and society at large (through the well-being outcome of HFE system design).

- Economic wealth of individuals and society at large (through the performance outcome of HFE system design). 
HFE helps to ensure that people do not get injured at work or while using products or receiving services, that work systems and product/service systems are profitable for companies and for society at large, and that work systems and product/service systems are accessible for people with a variety of capacities and aspirations.

\section{3. (Mis)match between potential value, perceived value, and provided value}

The previous analysis shows that HFE has the potential to provide value to all of the main stakeholders of system design. Each of the stakeholder groups could benefit from the contribution of HFE in systems design. The analysis also shows that stakeholders have different needs, and therefore have different views about the real value of HFE for them. For example, system actors (employees, product/service users) and some system influencers (e.g. governmental agencies focusing on health and safety) will appreciate the well-being outcome of HFE, whereas system experts (e.g. engineers) and system decision makers (e.g. managers) will appreciate the performance outcome of HFE.

However, the perceived value of HFE by all stakeholders is limited (Helander 1999, Neumann and Dul 2010). Some people believe that HFE focuses on well-being only; others say that it focuses on manufacturing only (e.g. heavy physical work), or on specific goods only (e.g. chair, computer mouse). Although there are many examples of highly successful companies with work systems, where workers are treated well from a physical, psychological, and organisational standpoint, become creative and productive members of the organisation, and are retained in the organisation, these 'winning' strategies are not always associated with HFE. Similarly, there are numerous examples of successful products that are based upon usability, ease of use, and perceptions of efficiency, such as iPhones, and other kinds of high tech gadgets. These devices are widely successful because of HFE features, yet the terms human factors or ergonomics are seldom heard when discussing these products, and hence HFE value is not perceived. These examples show that there is an implicit need for the value of HFE (performance and well-being), but not an awareness and explicit demand for the HFE discipline and profession. Hence, there is limited recognition and appreciation of how HFE can contribute to healthy, safe, comfortable and efficient work and product/service systems.

Although the role of HFE in enhancing well-being can be a strong value proposition for some stakeholder groups, i.e. system actors and system influencers, this may not be sufficient for other stakeholder groups, in particular, systems experts and system decision makers who primarily focus on the performance value of HFE. In many sectors, the provided value by the HFE community (in research and practice) focuses on wellbeing, and HFE specialists then have stronger relationships with the stakeholder group of system actors (that appreciate this goal) than with the stakeholder groups of systems experts and system decision makers (that are strongly interested in the performance outcome). In addition, the relationships of the HFE community with certain system influencers (e.g. governments) often focus on well-being rather than on performance. For example, the IEA has stronger formal relationships with international organisations that focus primarily (though not solely) on well-being, e.g. International Labour Organisation (ILO), International Occupational Hygiene Association (IOHA), and the International Commission on Occupational Health (ICOH) than with organisations that focus primarily (though not solely) on performance (e.g. organisations representing industrial engineers, product designers, or managers). There may well be a similar imbalance for many local HFE societies and many individual HFE specialists.

As a result, the HFE community has a less developed value proposition and weaker relationships with dominant stakeholders (Mitchell et al. 1997) who have considerable power to influence system design, in particular organisations representing system experts (such as design organisations), and organisations representing system decision makers (such as management organisations). The HFE community has a more developed value proposition and stronger relationships with dependent stakeholders such as the group of system actors who are less able to influence system design, but have strong interest in its outcome. In conclusion, the stakeholder group of system actors primarily needs and benefits from the well-being value of HFE, and this has created an explicit demand for HFE from this group. The stakeholder groups of system experts and system decision makers primarily need the performance value of HFE. However, they do not always get this value and are generally not aware that HFE can provide this value, even though they have an implicit need for it. As a result, there is limited explicit demand for HFE from this group. Because this group of system experts and system decision makers is more powerful in the design process than the first group (system actors), the HFE community should strengthen its value proposition (with a focus on performance outcomes), and its communication and relationships with these stakeholder groups, as well as with the system influencers. This will help to increase demand for high-quality HFE 
(well-being and performance outcomes) and therefore increase HFE contributions to system design, resulting in more high-quality HFE applications ${ }^{6}$.

\section{Strategy for the future}

In Section 1, we stated that the potential of HFE is under-exploited. In Section 2, we showed that HFE has three fundamental characteristics (systems approach, design driven, joint performance and well-being outcomes) and that this combination is unique in comparison to other disciplines. The developments described in Section 3 indicate that systems are changing and will continue to change in the future, and that HFE can help to design systems that fit people so that well-being and performance outcomes are achieved in future systems. In Section 4, we found that HFE currently serves the main stakeholder group of system actors relatively well (with well-being outcomes), but that it needs to better serve the main other stakeholder groups (system experts, system decision makers) with highquality HFE. These stakeholder groups are more influential in system design than system actors and have a strong interest in performance. At the same, they may have only a limited view about what HFE could offer. Therefore, HFE should expand its reach to system experts and system decision makers, with greater emphasis on the performance goal, and on the diversity of application areas.

Therefore, we propose the following main strategy for the future of HFE:

To strengthen the demand for and the application of high-quality HFE (with the key elements of systems approach, design driven, and performance and well-being outcomes) for all stakeholders, in particular:

(1) Strengthening the demand for high-quality HFE by enhancing the awareness of stakeholders' need for highquality HFE (in particular, for system experts and system decision makers, emphasising performance) by:

(a) Communicating with specific stakeholders about the value of high-quality HFE in the language of the stakeholder.

(b) Building partnerships with these stakeholders and their representing organisations.

(c) Educating stakeholders to raise awareness of high-quality HFE and its contributions to system design.

(2) Strengthening the application of high-quality HFE by:

(a) Promoting the education of HFE specialists to apply high-quality HFE.

(b) Ensuring high quality standards of HFE applications and HFE specialists.

(c) Promoting HFE research excellence at universities and other organisations.

These two strategic elements are interrelated. Higher demand for high-quality HFE can lead to more high-quality HFE provided ('pull'), and more availability of high quality HFE can stimulate demand for high-quality HFE ('push'). Figure 2 depicts the 'HFE demand development cycle' representing the main strategy. The cycle applies to a given stakeholder group (system actors, system specialists, system decision makers, or system influencers) and combines three strategic elements:

(1) A stakeholder's demand for high-quality HFE, which can stimulate

(2) the application of high-quality HFE (with the three key characteristics), which can

(3) raise the stakeholder's awareness of the need for high-quality HFE, which may

(4) increase the stakeholder's demand for high-quality HFE.

The HFE community can take an active role in boosting this cycle by focusing on both the pull and push approaches. It can enhance the stakeholders' awareness of their need for high quality HFE. This can be done by communicating with stakeholders, by building partnerships with stakeholders, and by educating stakeholders (Karwowski 2007). This requires that HFE specialists can translate and integrate HFE objectives into stakeholders' strategies, policies and actions (Dul and Neumann 2009). As a result, there should be an increased demand for high-quality HFE. The HFE community can also enhance high-quality HFE applications. This can be done by educating high-quality HFE specialists, by ensuring high quality HFE applications and specialists, and by encouraging HFE research excellence at universities and other organisations (Buckle 2011). By reflecting on success stories (successful applications of highquality HFE) and the related challenges, HFE knowledge and professional practice can be further enhanced. Hence, the HFE community is the main actor in this proposed strategic change. It can operate at three levels: global HFE society (IEA), local societies (national and regional HFE societies, e.g. IEA Federated Societies and IEA networks) and individual (HFE researchers, HFE teachers/trainers, HFE consultants, HFE policymakers). 


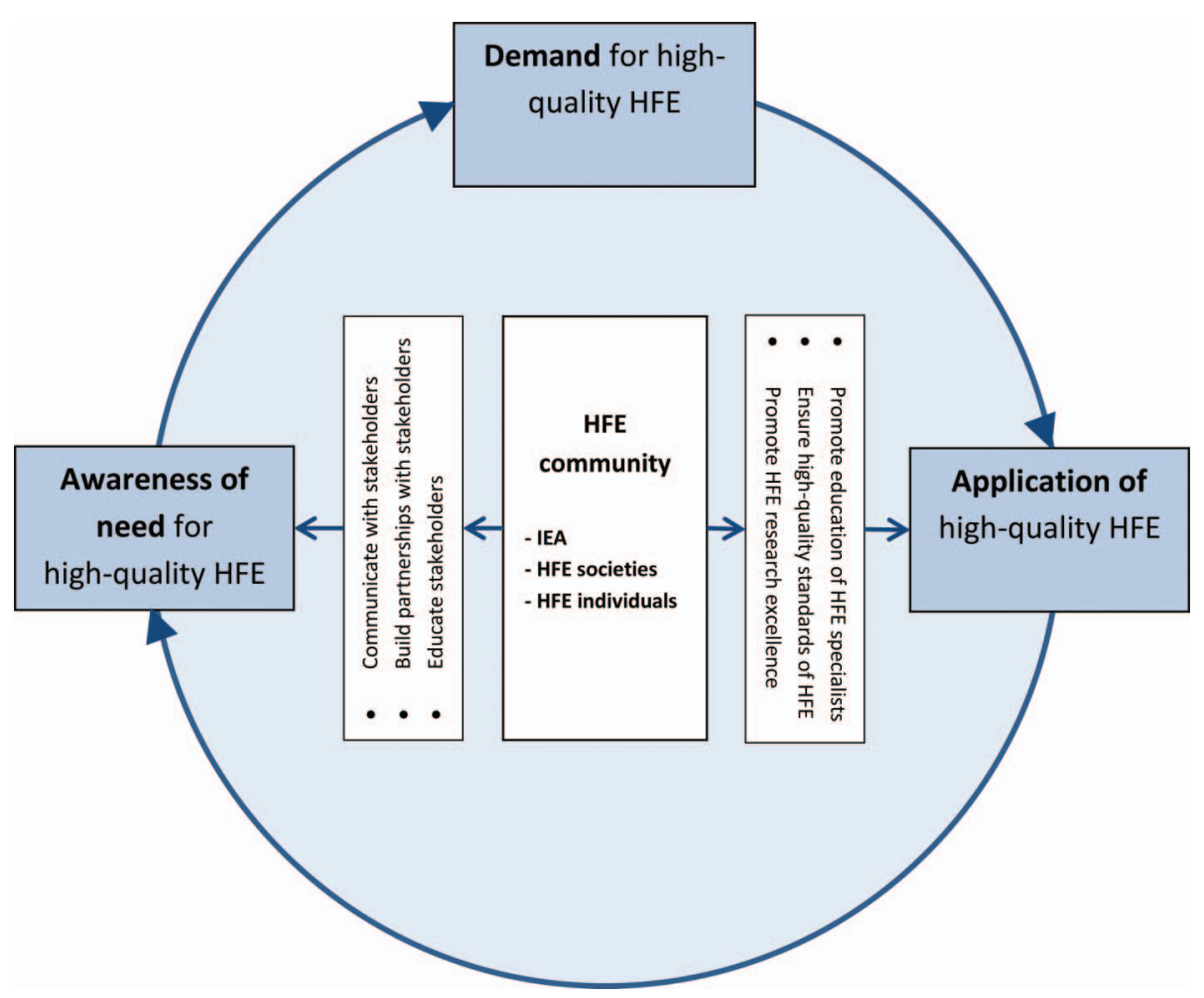

Figure 2. HFE demand development cycle.

\section{Strategy implementation}

The proposed main strategic direction is 'to strengthen the demand for and the application of high-quality HFE'. Adopting this main strategy has important consequences for the policies and practices of HFE societies and individuals, taken into account local differences and priorities.

The implementation of the strategy is an essential but complex endeavour that needs further development. We only touch upon two aspects: (1) developing an action plan by translating the strategy into actionable tasks, and (2) managing the development and implementation of the action plan.

In Section 6.1 (and the Appendix), we provide examples of possible strategic actions. We acknowledge that these strategic actions and their approach are not comprehensive, and need to be extended and addressed in detail. In Section 6.2, we propose a leadership role for the IEA to manage the development and implementation of the action plan.

\subsection{Examples of strategic actions}

Below, we give examples of actions that can be taken to realise the two main directions of the proposed strategy. Additional examples are provided in the Appendix. Ultimately, these strategic actions need to be translated into specific and effective actions by appropriate groups in the HFE community. In order to be successful, these actions must be 'smart': specific (e.g. specifying who, what, when, where, which, why), measurable (e.g. answering questions such as how much, how long), attainable (it must be possible to do them), realistic (people must be willing and able to work on them), and timely (e.g. setting time horizons for strategic actions such as 1, 2, 5 and even 10 years).

\section{Strengthening the demand for high-quality HFE by enhancing stakeholders' awareness of the need for high-quality HFE:}

- Communicating with dominant stakeholders (system experts, system decision makers), by emphasising the performance goal and the other key characteristics of HFE in their language (e.g. quantification of outcomes, cost-benefit analysis). Increasing these stakeholders' awareness and understanding of what high-quality HFE is by providing examples and success stories of high-quality HFE, but also examples of the negative effects 
resulting from the absence of high-quality HFE, and through recognition, awards and prizes for high quality HFE.

- Building strategic partnerships, in particular with system experts (e.g. professionals from the technical and social sciences), system decision makers (e.g. managers and other decision makers), and system influencers (e.g. local, national, and international governments and industry bodies, the general public (e.g. the media)). Long-term partnerships should ensure sustained improvements in both performance and well-being.

- Educating (future) stakeholders by showing the value of HFE at all educational levels and settings, from education at primary schools to education at institutes for professional education and universities, (e.g. engineering, design, business) as well as education beyond school systems. Because it is impossible that HFE specialists be present in all system designs, educating (future) system experts about the principles of HFE is necessary so that they can apply basic HFE principles in their design without the involvement of an HFE specialist, and can identify when there is a need to call in a HFE specialist for high-quality applications.

\section{Strengthening the application of high-quality HFE:}

- Promoting the education of high-quality HFE by formulating standards for high-quality HFE and for qualified HFE specialists (always paying attention to the three key characteristics: systems approach, design driven, performance and well-being) and by ensuring that education and training organisations adhere to these standards. Attracting students and experts from a wide range of disciplines to become HFE specialists in all three key characteristics. Applying high-quality HFE cannot be achieved by mechanically using a toolkit. Life-long education of HFE specialists (including insight from other fields such as industrial engineering, interaction design, cognitive psychology, human-movement studies, organisational behaviour, operations management, etc.) is essential to guarantee their competence to deliver high-quality HFE applications. For example, HFE specialists from human or health-related disciplines who may primarily focus on well-being outcomes of system design may need more education on performance outcomes and on building relationships with influential stakeholders such as system decision makers.

- Ensuring high quality standards of HFE applications and HFE specialists by promoting high-quality HFE in all activities of HFE societies and HFE individuals, and by ensuring the implementation of high-quality HFE standards by accreditation and certification bodies.

- Promoting HFE research excellence at universities and other organisations by promoting research and publications on high-quality HFE.

\subsection{Leadership role of the IEA}

We propose a leadership role for the IEA to manage the development and implementation of this strategy.

The IEA could act as a strategic leader in this process in several ways:

- By developing a global action plan to implement the strategy, with global consensus.

- By encouraging IEA federated societies and networks to set up their own action plans, each taking into account their specific context. The IEA should monitor and evaluate the development and implementation of these action plans and share lessons learned.

- By developing a plan of action at international level, targeting appropriate international institutions and organisations.

Different HFE groups and main stakeholder groups should be involved in this process so that the implementation plan fits specific needs and possibilities. IEA federated societies and networks should be the main contributors to this strategic action. Only they know the specificities of their national or regional context, the challenges they face, the opportunities they may exploit, and the people and organisations that may help them. IEA networks could play an important role as intermediate actors. The first objective of IEA federated societies and networks should then be to define a locally relevant plan of action to be developed with their members and shared at IEA level.

Such a global effort can work only if individual members of the federated societies understand it. In this perspective, it might be useful to have this text translated in the national language of the societies where English is not commonly used. 
Furthermore, other HFE organisations should also be involved. Certification bodies should be encouraged to examine their criteria for certification and to check whether these criteria are in agreement with the fundamental characteristics of high-quality HFE described in this paper. Professional organisations of HFE specialists that are not part of the IEA should also be approached to ensure shared views on the nature of HFE and its high quality delivery.

Finally, the major stakeholders must be involved because the strategy focuses on showing and delivering value to them. It is then crucial to understand the views of stakeholders on HFE and its benefits, and how HFE specialists can be their partners in system design.

Over the next decade, the design and implementation of this plan will be the main objective and a major activity of the IEA Executive Committee and the IEA Council, as well as of the local HFE societies. Successful implementation of the strategy in the long term, spearheaded by the IEA, is only possible if the IEA sets appropriate conditions such as continuity of governance, effective mobilisation of federated societies, and sufficient resources. This might require serious reconsideration of the current IEA organisation.

\section{Concluding remarks}

This paper offers the HFE community a strategic direction for the future of the HFE discipline and profession that could lead to the development of new strategies, tactics and operations within specific local contexts. Developing and implementing a strategic action plan for the HFE discipline and profession at large requires a long lasting and joint effort of the entire HFE community. The result will be rewarding. The external community will recognise the HFE discipline and profession as a crucial partner for successful systems design.

\section{Acknowledgements}

We would like to thank many human factors/ergonomics specialists who have provided their personal input to the work of the committee and/or who commented on earlier versions of this paper: F. Javier Llaneza Alvarez, ArcelorMittal, Spain; Alexey Anokhin, National Research Nuclear University 'MEPhI', Russia; Tomas Berns, Ergolab AB, Sweden; Verna Blewett, University of South Australia, Australia; Guy André Boy, Florida Institute of Technology, USA; Bob Bridger, INM, UK; Ole Broberg, Technical University of Denmark, Denmark; Alexander Burov, Institute of Gifted Child, Ukraine; David C. Caple, David Caple \& Associates, Australia; Alan Chan, City University of Hong Kong, Hong Kong; Wen-Ruey Chang, Liberty Mutual Research Institute for Safety, USA; Pierre-Henri Dejean, University of Technology of Compiègne, France; Mica Endsley, SA Technologies, USA; Patricia Ferrara, Technoserve Inc., Mozambique; Margo Fraser, Association of Canadian Ergonomists, Canada; Yushi Fujita, Research Department, Japan; Somnath Gangopadhyay, University of Calcutta, India; Sylva Gilbertova, SAZ, Czech Republic; Matthias Göbel, Rhodes University, South Africa; José Orlando Gomes, Federal University of Rio de Janeiro, Brazil; Richard Goossens, Delft University of Technology, the Netherlands; Alan Hedge, Cornell University, USA; Martin Helander, Nanyang Technological University, Singapore; Magne Helland, Buskerud University College, Norway; Veerle Hermans, IDEWE and Vrije Universiteit Brussel, Belgium; François Hubault, Université Paris 1, France; Sheue-Ling Hwang, National Tsing-Hua University, Taiwan; Andrew S. Imada, A. S. Imada \& Associates, USA; Christina Jonsson, Swedish Work Environment Authority, Sweden; Halimahtun Khalid, Damai Sciences Sdn Bhd, Malaysia; Jung-Yong Kim, Hanyang University, South Korea; Karsten Kluth, University of Siegen, Germany; Kazutaka Kogi, Institute for Science of Labour, Japan; Ernst Koningsveld, TNO, The Netherlands; Rabiya Lallani, Human Factors North Inc., Canada; Johan Molenbroek, Delft University of Technology, the Netherlands; Karen Lange Morales, National University of Colombia, Colombia; John Lee, University of Wisconsin, USA; Jean-Luc Malo, Vincent Ergonomie, Canada; Nicolas Marmaras, National Technical University of Athens, Greece; Svend Erik Mathiassen, University of Gävle, Sweden; Dave Moore, SCION Research, New Zealand; Dimitris Nathanael, National Technical University of Athens, Greece; Patrick Neumann, Ryerson University, Canada; Ian Noy, Liberty Mutual Research Institute for Safety, USA; Clas-Hakan Nygard, Tampere University, Finland; Enrico Occhipinti, University of Milan, Italy; Ahmet F. Ozok, Istanbul Kültür University, Turkey; Gunther Paul, University of South Australia, Australia; Ruud Pikaar, Ergos Engineering \& Ergonomics, the Netherlands; Anna Ptackova, Skoda, Czech Republic; David Rempel, University of California, USA; Luz Mercedes Saenz, University Pontificia Bolivariana, Colombia; Martha Helena Saravia, Pontifical University Javeriana, Colombia; Christopher Schlick, Aachen University, Germany; Schu Schutte, Council for Scientific and Industrial Research, South Africa; Patricia Scott, Rhodes University, South Africa; Paul Settels, ING, the Netherlands; Barbara Silverstein, SHARP - Washington State Department of Labor \& Industries, USA; Marcelo Soares, Federal University of Pernambuco, Brazil; Cláudia Stamato, PUC-Rio - Pontifical Catholic University of Rio de Janeiro, Brazil; Carol Stuart-Buttle, Stuart-Buttle Ergonomics, USA; Andrew Thatcher, University of Witwaterstrand, South Africa; Andrew Todd, Rhodes University, South Africa; Takashi Toriizuka, Nihon University, Japan; John Walter, Technoserve Inc., Mozambique; Eric Min-Yang Wang, National Tsing Hua University, Taiwan; Christine Waring, Latrobe Regional Hospital, Australia; Klaus J. Zink, University of Kaiserslautern, Germany; Moustafa Zouinar, Orange labs - France telecom, France; Gert Zülch, Karlsruhe Institute of Technology, Germany.

Furthermore, input was received from a group of $17 \mathrm{PhD}$ candidates and professors of the Conservatoire National des Arts et Métiers (CNAM), Paris, France. Roger Haslam (editor of Ergonomics) and three anonymous reviewers are thanked for their comments. Financial support for this project was provided by the International Ergonomics Association (IEA). 


\section{Notes}

1. In the present paper, we consider 'ergonomics' and 'human factors' to be synonymous, and we adopt the IEA definition of the discipline (IEA 2000): 'Ergonomics (or human factors) is the scientific discipline concerned with the understanding of the interactions among humans and other elements of a system, and the profession that applies theoretical principles, data and methods to design in order to optimise human well-being and overall system performance.' To identify the discipline throughout this paper, we have selected the name 'human factors/ergonomics' (HFE). By accepting this definition, we also accept the view that HFE is a scientific discipline and not only a (multidisciplinary) approach to problem solving. We also accept that this definition reflects a more positivist rather than a more constructivist view on the discipline.

2. The committee consists of Jan Dul (Chair, Netherlands), Ralph Bruder (Germany), Peter Buckle (UK), Pascale Carayon (USA), Pierre Falzon (France), William S. Marras (USA), John R. Wilson (UK), and Bas van der Doelen (Secretary, Netherlands).

3. HFE focuses primarily on two types of systems: work systems (with workers in private or public organisations) and products (consumer or business goods or services). Traditionally 'work' is a central issue in HFE, as indicated by the etymology of the word ergonomics (ergo = work). However, HFE is concerned with all kinds of activities that go beyond (paid) work and includes activities carried out by a range of users, e.g. customers, citizens, patients, etc. with different characteristics (e.g. age), in a range of domestic, leisure, sport, transport and other environments. When we use the words 'work system' it includes other living systems.

4. Other contributors are the effort taken by the human independently of the environment, as well as contributions from other components of the system.

5. In this paper, we do not use the term 'optimisation' in its mathematical meaning of finding a best available value for a given objective function. Instead, optimisation refers to finding design solutions to maximise both well-being and performance, which may require making trade-offs between both objectives.

6. By high-quality HFE we mean that the three core elements of HFE: systems approach, design driven and performance and well-being outcomes, are taken into consideration when defining problems and formulating solutions. Without these key elements, the HFE approach is limited. High-quality HFE includes approaches with a focus on specific aspects of people (e.g. physical), on specific aspects of the environment (e.g. technical), on specific outcomes (e.g. well-being), or with limited links to design, as long as limitations of the specific approach and how to tackle these are addressed ('contextualisation'). This can be done, for example, by collaborating with other specialists, planning broader approaches at later stages, or acknowledging the limitations of problem definitions and solutions. Specific approaches may occur e.g. when the HFE specialist can have only a limited role in the design process, or when there are practical or other restrictions for a broader scope (e.g. only simple solutions are feasible), for instance, in economically developing countries (Kogi 2007). As a strategic direction, high-quality HFE approaches are preferred over limited approaches as the combination of core elements of HFE is a unique value proposition for all stakeholders.

\section{References}

Brewer, J.D. and Hsiang, S.M., 2002. The 'ergonomics paradigm': foundations, challenges and future directions. Theoretical Issues in Ergonomics Science, 3 (3), 285-305.

Broberg, O., 1997. Integrating ergonomics into the product development process. International Journal of Industrial Ergonomics, 19 (4), 317-327.

Bruder, R., 2000. Ergonomics as mediator within the product design process. Human Factors and Ergonomics Society Annual Meeting, 44 (8), 20-23.

Buckle, P., 2011. The perfect is the enemy of the good. Ergonomics, 54 (1), 1-11.

Buckle, P. and Buckle, J., 2011. Obesity, ergonomics and public health. Perspectives in Public Health, 131 (4), $170-176$.

Caple, D., 2008. Emerging challenges to the ergonomics domain. Ergonomics, 51 (1), 49-54.

Carayon, P., 2006. Human factors of complex sociotechnical systems. Applied Ergonomics, 37 (4), $525-535$.

Carayon, P. and Smith, M.J., 2000. Work organization and ergonomics. Applied Ergonomics, 31 (6), 649-662.

Delios, A., 2010. How can organizations be competitive but dare to care? Academy of Management Perspectives, 24 (3), $25-36$.

Drury, C.G., 2008. The future of ergonomics/the future of work: 45 years after Bartlett (1962). Ergonomics, 51 (1), 14-20.

Dul, J. and Ceylan, C., 2011. Work environments for employee creativity. Ergonomics, 54 (1), 12-20.

Dul, J. and Neumann, W.P., 2009. Ergonomics contributions to company strategies. Applied Ergonomics, 40 (4), $745-752$.

Falzon, P., 2005. Ergonomics, knowledge development and the design of enabling environments. In: HWWE'2005, humanizing work and work environment conference, December 2005, Guwahati, India: Allied Publishers.

Falzon, P., Nascimento, A., Gaudart, C., Piney, C., Dujarier, M.-A. and Germe, J.-F., 2012. Performance-based management and quality of work: an empirical assessment. WORK: A Journal of Prevention, Assessment \& Rehabilitation, (forthcoming).

Gangopadhyay, S., Das, B.B., Das, T., and Ghoshal, G., 2004. Prevalence of Musculoskeletal Disorders among pre-adolescent agricultural workers of West Bengal, India. Ergonomics SA. Journal of the Ergonomics Society of South Africa, 16 (1), $2-14$.

Gibson, C.B. and Gibbs, J.L., 2006. Unpacking the concept of virtuality: The effects of geographic dispersion, electronic dependence, dynamic structure, and national diversity on team innovation. Administrative Science Quarterly, 51 (3), 451-495.

Hedge, A. and Spier, A.L., 2008. On the future of ergonomics: HFES members speak out. HFES Bulletin, 51 (2), 1-2.

Helander, M., 1999. Seven common reason to not implement ergonomics. International Journal of Industrial Ergonomics, 25 (1), $97-101$.

Helander, M.G., 1997. Forty years of IEA: Some reflections on the evolution of ergonomics. Ergonomics, 40 (10), 952-961.

Hendrick, H.W., 1991. Ergonomics in organizational design and management. Ergonomics, 34 (6), $743-756$.

Hollnagel, E., 2001. The future of ergonomics (guest editorial). Theoretical Issues in Ergonomics Science, 41 (2), $219-221$. 
IEA, 2000. The Discipline of Ergonomics. International Ergonomics Association. Available from: www.iea.cc [Accessed 11 January 2012].

Ilmarinen, J., 2006. Towards a longer worklife: ageing and the quality of worklife in the European Union. Helsinki: FIOH Bookstore.

Japan Ergonomics Society, 2006. The JES Ergonomics Roadmap. Japan Ergonomics Society.

Karwowski, W., 2006. From past to future: building a collective vision for HFES 2020+. HFES Bulletin, 49 (11), 1-3.

Karwowski, W., 2007. Toward an HF/E-literate society. HFES Bulletin, 50 (2), 1-2.

Kogi, K., 2007. Action oriented use of ergonomic checkpoints for healthy work design in different settings. Journal of Human Ergology, 36, 37-43.

Mitchell, R.K., Agle, B.R., and Wood, D.J., 1997. Toward a theory of stakeholder identification and salience: Defining the principle of who and what really counts. Academy of Management Review, 22 (4), 853-886.

Moray, N., 2000. Culture, politics and ergonomics. Ergonomics, 43 (7), 858-868.

Neumann, W.P. and Dul, J., 2010. Human factors: Spanning the gap between OM and HRM. International Journal of Operations \& Production Management, 30 (9), 923-950.

Noro, K. and Imada, A.S., 1991. Participatory Ergonomics, London: Taylor and Francis.

Noy, I., 1995. Twelfth triennial congress of the international ergonomics association/douzieme congres triennial de l'association internationale d'ergonomie - 'bridging the gap/S'unir pour l'avenir' - guest editorial. Ergonomics, 38 (8), $1539-1541$.

Noy, I., 2000. Ergonomics; the silent engine in the evolution of human society. Presidential address, 14th IEA Triennial Congress, 31 July 2000. San Diego, USA.

Patel, H., Pettitt, M., and Wilson, J.R., 2012. Factors of collaborative working: a framework for a collaboration model. Applied Ergonomics, 43 (1), 1-26.

Pfeffer, J., 2010. Building sustainable organizations: the human factor. Academy of Management Perspectives, 24 (1), $34-45$.

Pot, F.D. and Koningsveld, E.A., 2009. Quality of working life and organizational performance-two sides of the same coin? Scandinavian Journal of Work, Environment \& Health, 35 (6), 421-428.

Proctor, R.W., Nof, S.Y., Yih, Y., Balasubramanian, P., Busemeyer, J.R. and Carayon, P., 2011. Understanding and improving cross-cultural decision making in design and use of digital media: a research agenda. International Journal of HumanComputer Interaction, 27 (2), 151-190.

Rasmussen, J., 2000. Human factors in a dynamic information society: where are we heading? Ergonomics, 43 (7), 869-879.

Riedel, R. and Mueller, E., 2009. Production management and supply chain management in a global context. International Journal of Manufacturing Technology and Management, 16 (3), 300-317.

Schlick, C.M., 2009. Industrial engineering and ergonomics in engineering design, manufacturing and service. In: C.M. Schlick, ed. Industrial engineering and ergonomics - vision, concepts, methods an tools. Berlin: Springer.

Stanton, N.A. and Stammers, R.B., 2008. Bartlett and the future of ergonomics. Ergonomics, 51 (1), 1-13.

Wilson, J.R., 2000. Fundamentals of ergonomics in theory and practice. Applied Ergonomics, 31 (6), $557-567$.

Wilson, J.R., Ryan, B., Schock, A., Ferreira, P., Smith, S. and Pitsopoulos, J., 2009. Understanding safety and production risks in rail engineering planning and protection. Ergonomics, 52 (7), 774-790.

Woods, D. and Dekker, S., 2000. Anticipating the effects of technological change: a new era of dynamics for human factors. Theoretical Issues in Ergonomics Science, 1 (3), 272-282.

Zink, K.J., 2005. From industrial safety to corporate health management. Ergonomics, 48 (5), 534-546.

Zink, K.J., 2006. Human factors, management and society. Theoretical Issues in Ergonomics Science, 7 (4), $437-445$. 


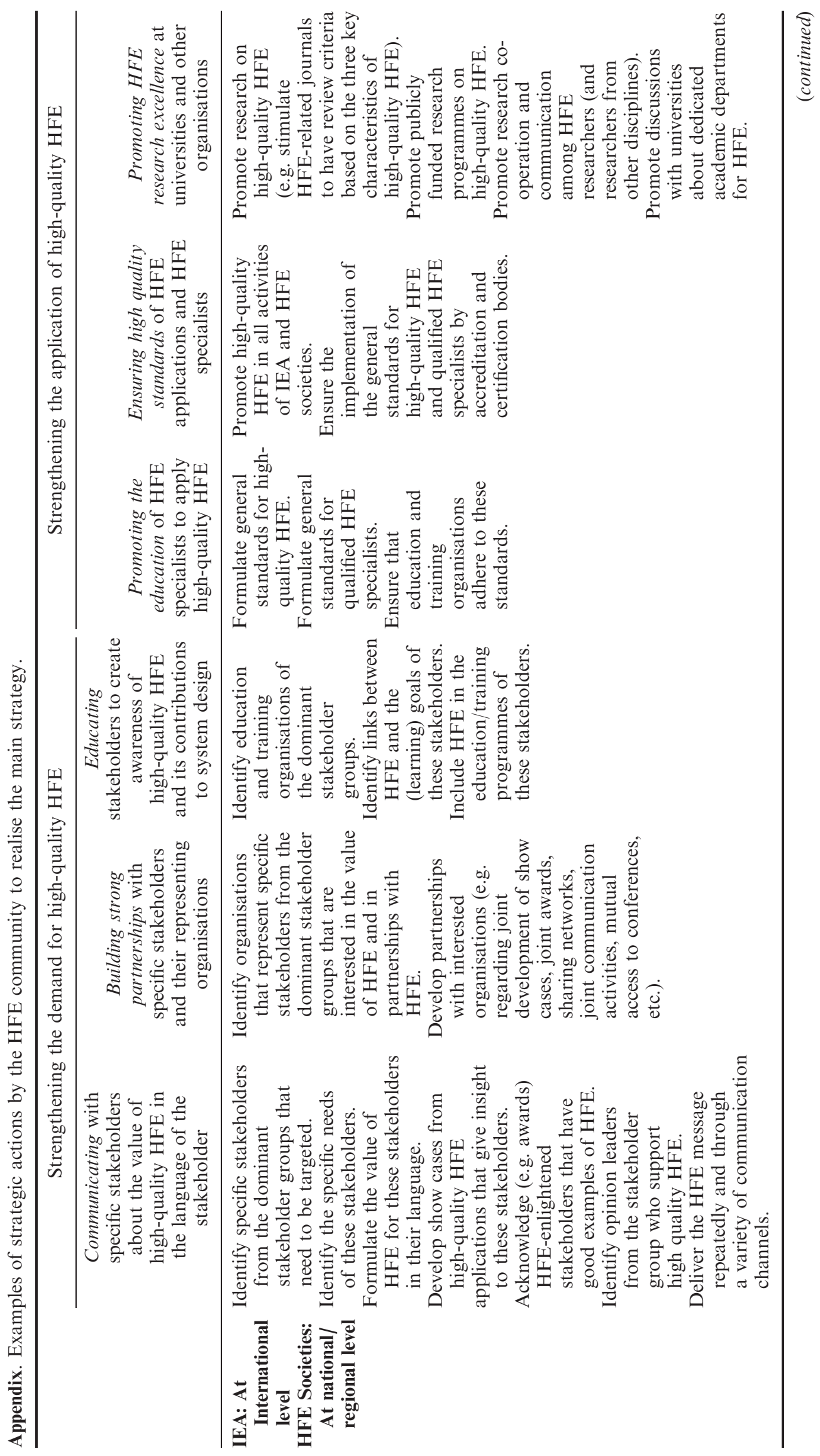




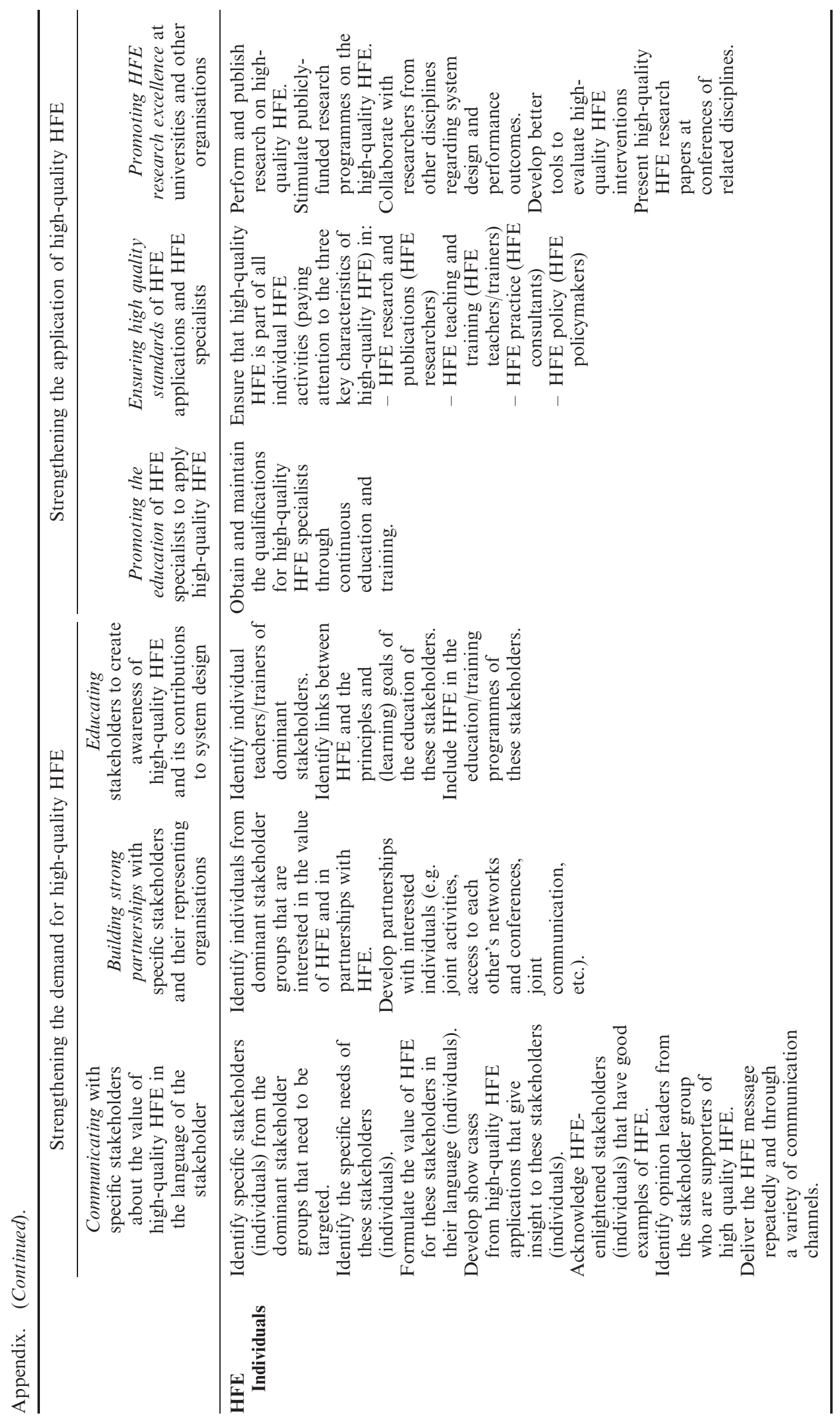

